\title{
THE ANATOMY OF PHRENIC NERVE TERMINATION AND THE MOTOR INNERVATION OF THE DIAPHRAGM
}

\section{BY}

\author{
G. S. MULLER BOTHA \\ From the Department of Surgery, Queen Elizabeth Hospital, Birmingham
}

(RECEIVED FOR PUBLICATION SEPTEMBER 26, 1956)

The more frequent diagnosis of sliding hiatal hernia has focused surgical attention on the crural fibres of the diaphragm. The part played by the muscular hiatus in "the closing mechanism" between stomach and oesophagus is, however, still undecided. Various experimental methods of dividing crural muscle and phrenic nerve have been tried at different centres to evaluate the importance of the muscular hiatus. These sections and the relevant clinical considerations necessitate a precise knowledge of phrenic nerve termination, and therefore a series of anatomical and experimental investigations was carried out in man as well as in the common laboratory animals.

\section{Anatomical Material}

HuMAN.-Diaphragms were carefully removed at necropsy, spread out between layers of cotton-wool in $10 \%$ formol saline, and dissected when fixed. Fifty specimens were studied. The age of the patients varied from prematurity to 85 years, 45 years being the average. In addition, numerous dissections were performed at necropsy with the organs in situ.

Animals.-Diaphragms of the rat, ferret, rabbit. cat, dog, and monkey were examined in situ and after removal. Diaphragms of a further 11 species were examined in less detail.

\section{METHOD}

(1) The peripheral musculature was most satisfactorily studied in situ for signs of intercostal innervation.

(2) The distal 1-2 in. of the phrenic nerves as well as their macroscopical branches were isolated and followed.

(3) Communications from the vagi, sympathetic, and splanchnic nerves were carefully looked for.

(4) In some specimens the under surface was examined for ganglia.

\section{Findings}

Human.-I have found no exception to the general pattern of innervation of the diaphragm, a fact to be expected in such a basic structure as the phrenic nerve. On the right side it descends imme- diately lateral or postero-lateral to the inferior $\overrightarrow{\vec{H}}$ vena cava, though in a few cases it was antero- 0 lateral. The left phrenic nerve lies anterior and far out as it descends over the antero-lateral angle of the pericardial base to reach the diaphragm 3 at a muscular or tendinous area (Fig. 1). Both nerves always divide into a variable number of $⿱ 乛$ branches, from two to seven (Fig. 2). The classi- $\overrightarrow{0}$ cal impression of only three branches is erroneous. . The branches vary in size and the thickness bears no relationship to the area supplied. The phrenic nerves in every case branched above the diaphragm, the distance varying from a few milli- ڤ metres to more than $2 \mathrm{~cm}$. The branches can $\stackrel{\circ}{\circ}$ only be exposed after removal of the fatty pads $\underset{F}{\Rightarrow}$ that are generally present. The average finding $\frac{0}{3}$ was three to five branches separating into anterior, lateral, and posterior directions, $0.5-1 \mathrm{~cm}$. above the diaphragm. The postero-medial branch was usually the biggest, absolutely constant, and always running in the same direction. No ganglionic enlargement was observed either before or after $\underset{-}{-}$ branching of the parent trunks. The branches 3 . diverge, enter the muscle or central tendon, and 8 run obliquely for a varying distance in its sub- $\overline{3}$ stance. They then appear on the under surface 0 of the diaphragm and radiate deep to the sub-? phrenic fascia, whence numerous filaments innervate the muscle fibres. Some filaments enter the neighbouring muscle fibres from above or as the $\mathcal{N}$ nerve branches pierce the muscle, and some could N be traced to the peripheral edge of the diaphragm. N

The postero-lateral branches differ on the two sides (Fig. 3). On the right it is short, thick, and always passes posterior to the vena cava, being $\frac{0}{\Phi}$

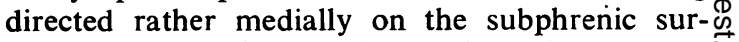
face to the right hiatal margin. Few or no branches are given off anteriorly. Posteriorly, ${ }_{0}$ long filaments supply the costovertebral arches, $\mathbb{\mathbb { D }}$ whilst short superficial filaments innervate the $\frac{O}{\mathbb{Q}}$ crural fibres on the right side of the hiatus: no 2 fibres are given to muscle on the left of the hiatus. The postero-medial branch on the left side is long, 8 


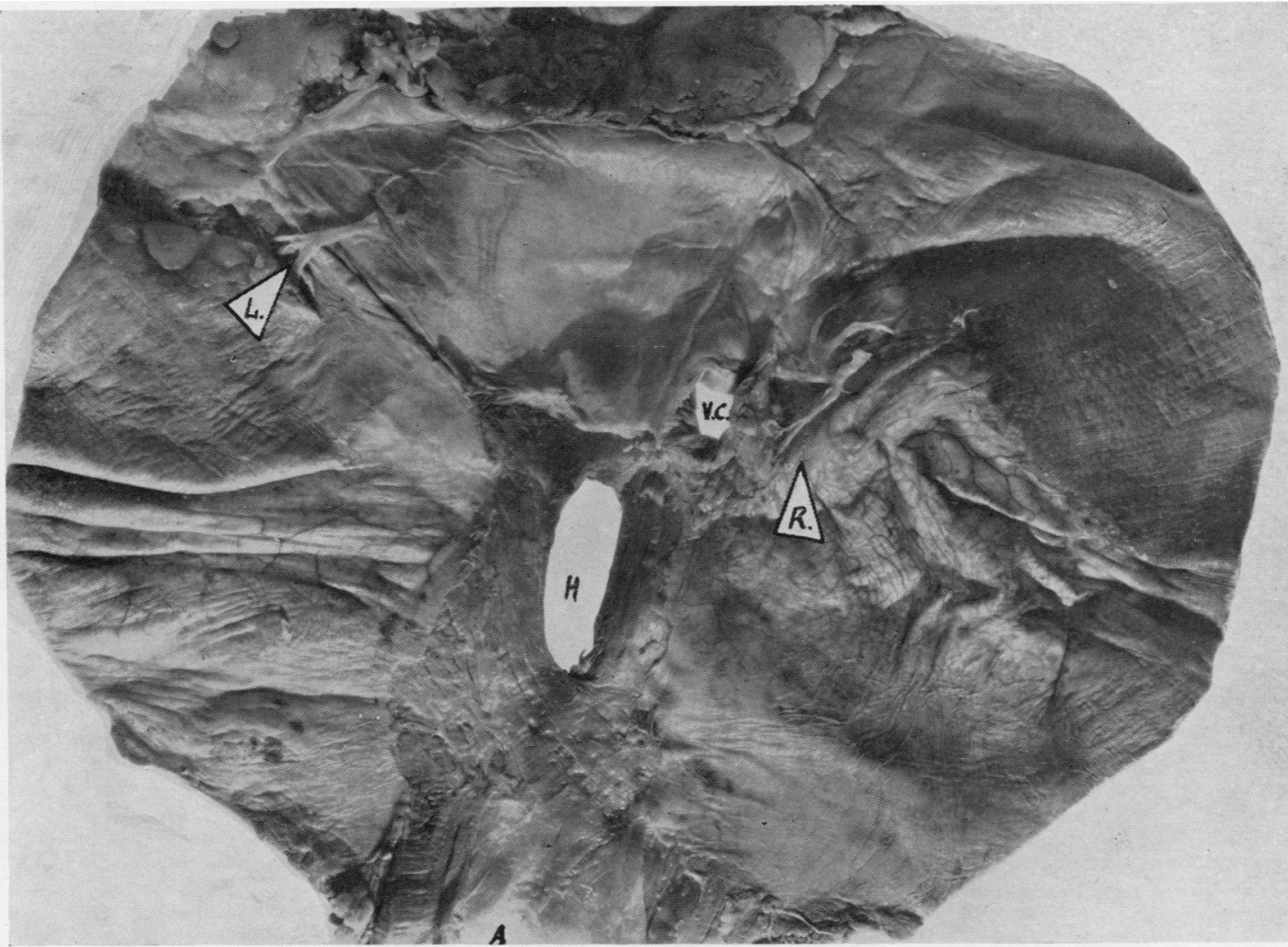

FIG. 1. - The termination of the phrenic nerves as seen from above. $L==$ left phrenic nerve. $\quad R .=$ right phrenic nerve. V.C. $=$ vena cava. H. =oesophageal hiatus. A.=aorta.

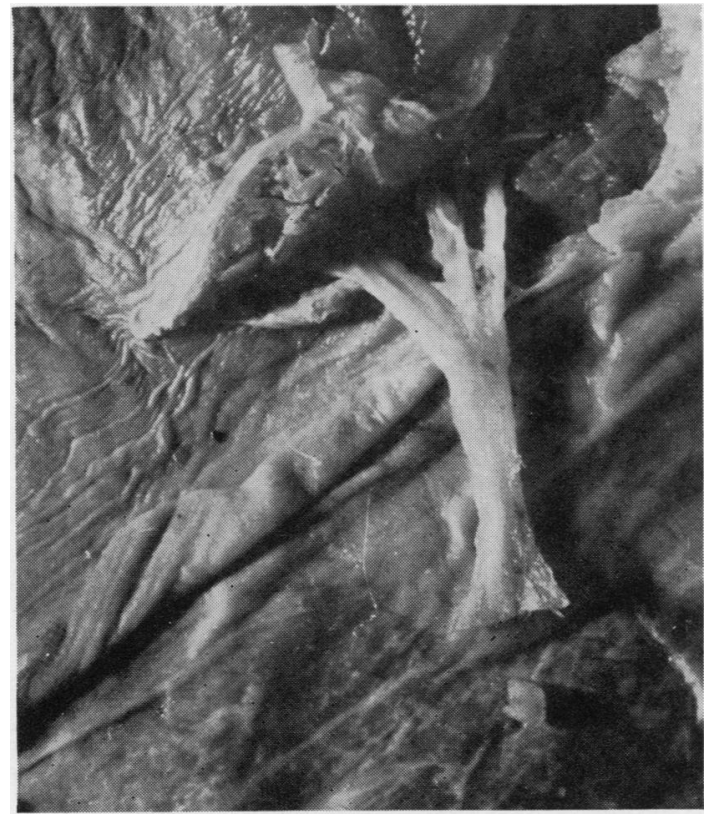

FIG. 2a.-The left phrenic nerve ends here in the classical three branches.

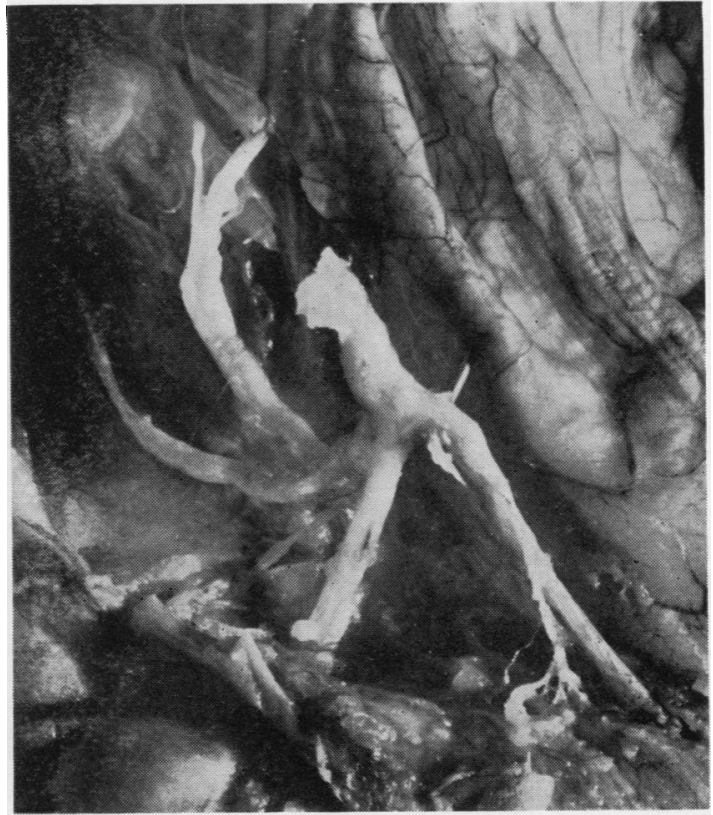

Fig. 2b. - The right phrenic nerve terminates in four main and several subsidiary branches. 


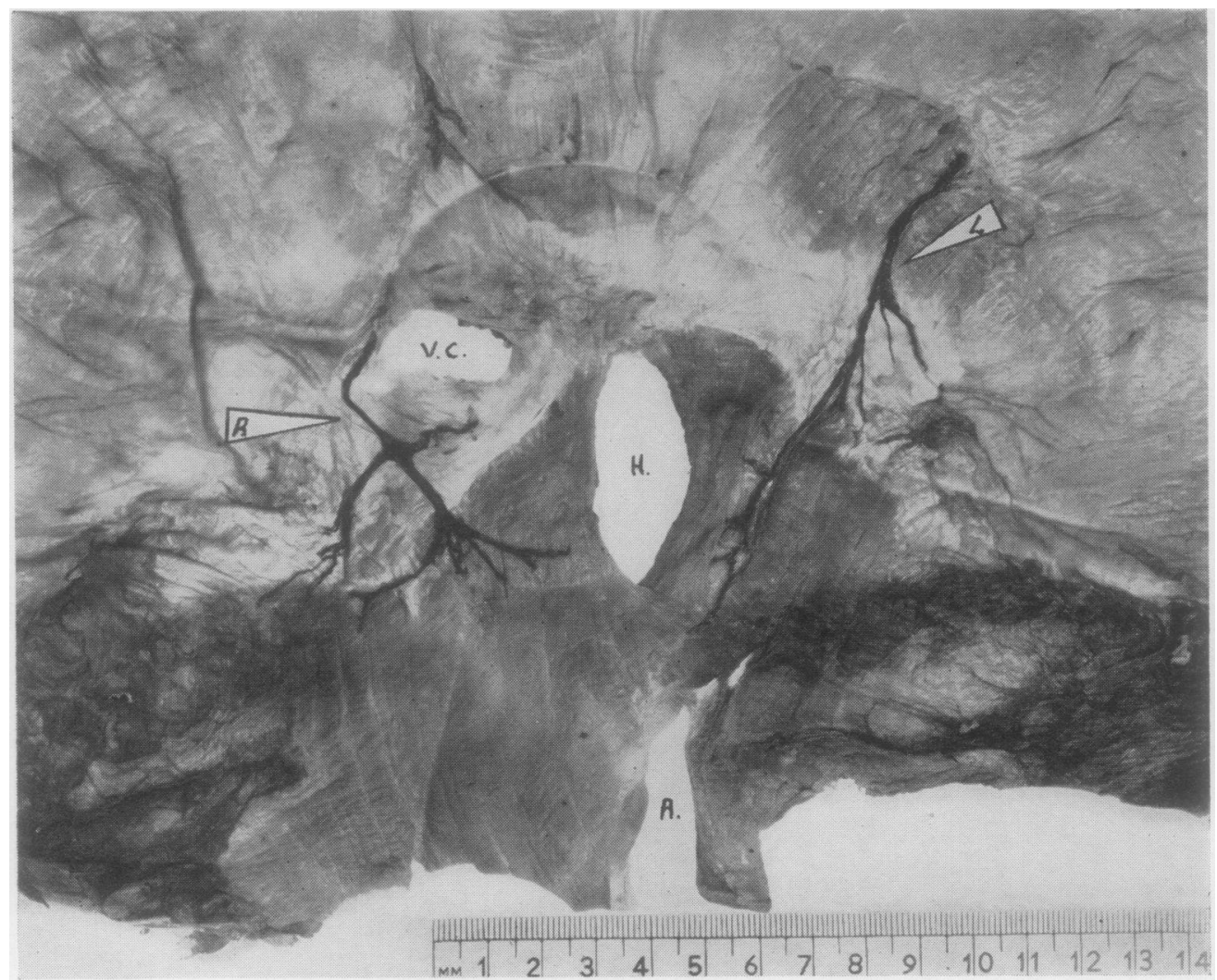

FIG. 3.-The postero-medial branches seen from under the surface.

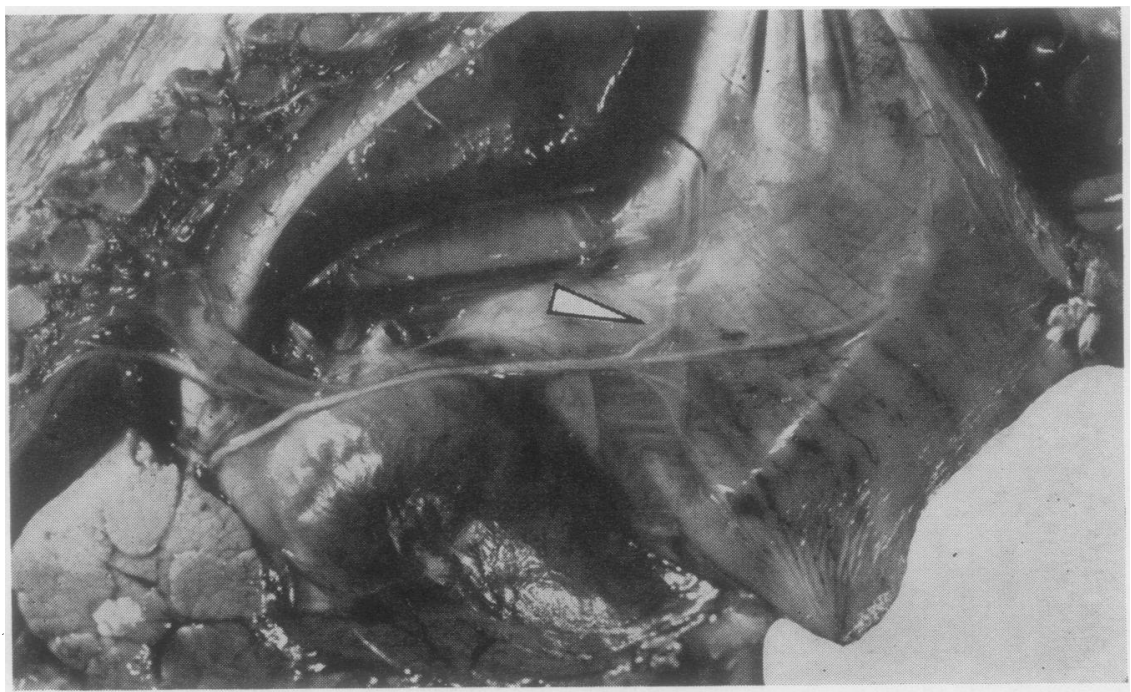

Fig. 4.-The arrow indicates the postero-medial branch of the left phrenic in a $20 \mathrm{~cm}$. sheep foetus. 
slender, and directed towards the vertebral column with numerous branches from its medial and lateral aspect. After piercing the diaphragm it runs on its under surface across the central tendon to the left hiatal margin. At first it lies superficially, but it soon enters the substance of the crus and descends within the muscle about one-half to three-quarters of an inch to the left of the hiatus. Long filaments to the costovertebral arches are given off before it enters the muscle, and short filaments to the crural fibres as it descends in its substance. Histological examination of the phrenic nerves at and above the sites of branching revealed no sign of ganglion formation. It supplies all muscle to the left of the hiatus.

Small filaments from the intercostal nerves were seen to enter the peripheral diaphragmatic muscle. The vagus had no connexions with the hiatus, but numerous filaments from the coeliac plexus ramified on the under surface of the diaphragm. Some fibres appeared to arise from the sympathetic and splanchnic trunks. Ganglia were noticed only on the right subdiaphragmatic surface in some cases.

ANimaLs. - The pattern is essentially the same in all the animals. The right phrenic nerve innervates muscle fibres on the right side only of the

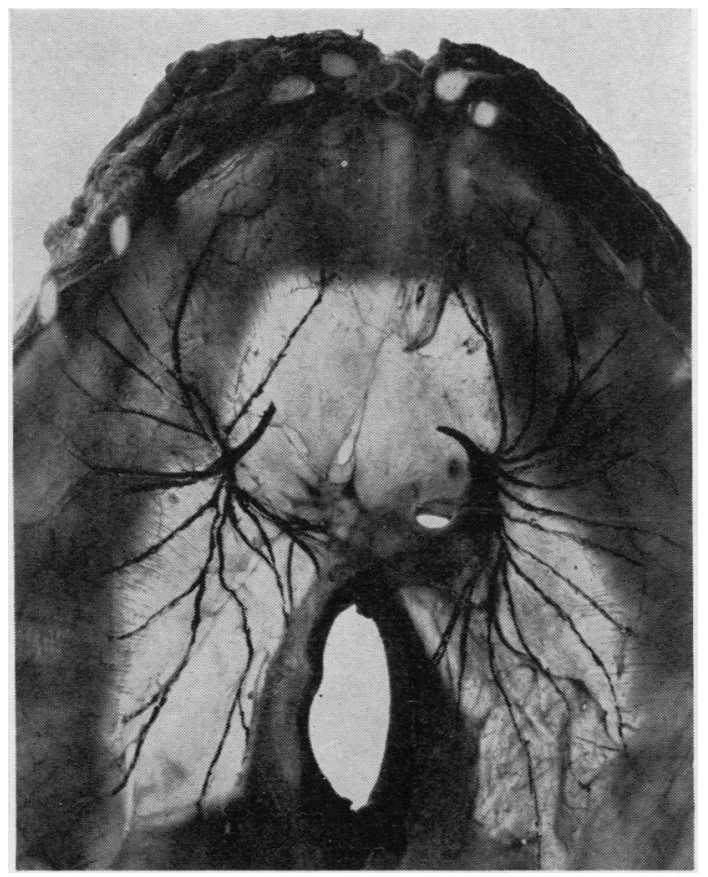

FIG. 5.-Phrenic nerve branches in a monkey. Diaphragm seen from above. hiatus, whilst the left supplies the muscle to the left of the oesophagus. The postero-lateral branch is much sturdier, forming a distinct branch almost exclusively for the crura (Fig. 4). It arises as a separate branch high up in some species $(2-3 \mathrm{~cm}$. in rabbit, $4-5 \mathrm{~cm}$. in pig, and even higher in others). The number of branches varied from two to nine (Fig. 5). No ganglia were noticed above the diaphragm in any of these preparations. Intercostal and autonomic connexions were very much the same as in the human, but no sympathetic ganglia were found below the diaphragm.

Technical difficulties are considerable in isolating thread-like nerve filaments macroscopically and nerve dissections give no indication of function. Nerve stimulation experiments were employed to study this aspect.

\section{Nerve Stimulation Experiments}

Nerve stimulation experiments were performed in the rat, mouse, hamster, guinea-pig, rabbit, ferret, monkey, pig, cat, and dog. A thoracolumbar incision exposed the diaphragm from above and below during controlled endotracheal anaesthesia (Botha and Nunn). Faradic stimulation of the splanchnic nerves, the sympathetic chain, the vagi, and the phrenic nerve and its branches was carried out whenever possible in all the species.

FINDINGS.-Phrenic nerve stimulation always resulted in contraction of the whole of the ipsilateral half of the diaphragm. No peripheral or crural fibres failed to contract. In some animals the postero-lateral branch was stimulated after section of the main trunk. All crural fibres always contracted on the ipsilateral side of the hiatus, irrespective of whether they were anatomically part of the right or left crus. No contralateral contraction was observed. No muscle fibres contracted during stimulation of the autonomic nerves in the lower thorax, although oesophageal and bowel tone was obviously affected.

\section{Nerve Degeneration EXPERIMENT}

At thoracotomy in a full-grown rabbit the left phrenic nerve was sectioned $3 \mathrm{~cm}$. above the diaphragm. Radiological examination two months later revealed the left cupola to be high and restricted in movement. Five months later laparotomy was performed. The left dome was $2 \mathrm{~cm}$. higher than the right. During inspiration only the right half contracted. No sign of contraction was noticed in the left half. The animal was killed 


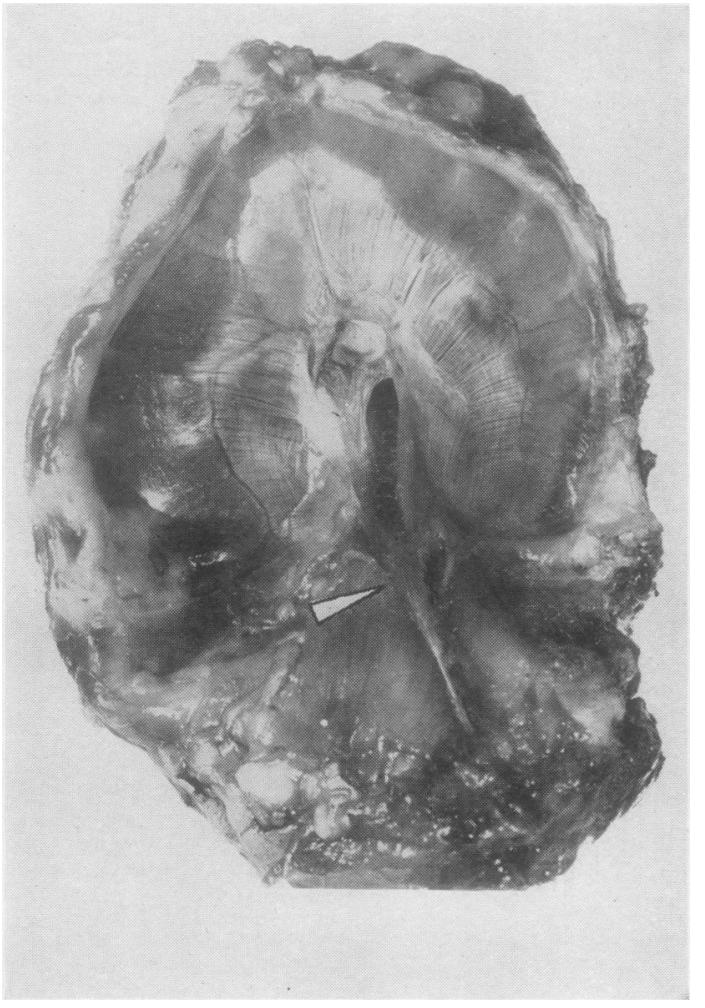

FIG. 6.-The diaphragm of a rabbit five months after left phrenicotomy.

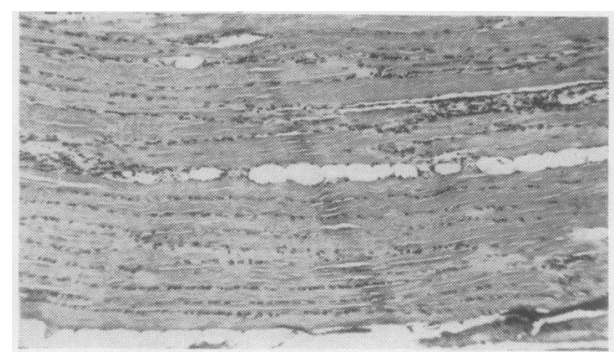

Fig. 7a.-The right crus of the diaphragm in Fig. 6 at the level of the arrow.

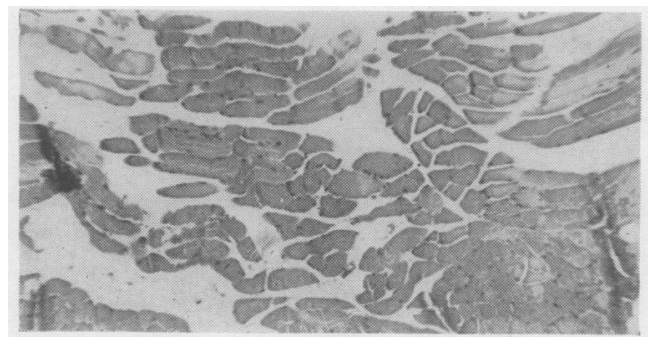

FIG. 7b.-The left crus showing fragmentation of the muscle fibres. and further examined. The left half of the diaphragm was small, flabby, and thin (Fig. 6). The white ligamentous strands contrasted markedly with the normal red and firm right side. All crural fibres to the left of the hiatus were atrophic, pale, and rubbery, resembling very closely the muscle fibres of the lumbar arches and the peripheral diaphragm. Histological examination revealed fragmented, poorly staining atrophic muscle fibres, scanty in nuclei and partly replaced by fibro-fatty tissue (Fig. 7).

\section{Discussion}

The macroscopical dissections leave no doubt that the phrenic nerve is the main motor supply to diaphragmatic muscle but it does not exclude motor fibres from other sources. Luschka (1853), Cavalié (1896), Schwalbe (1881), Ellenberger and Baum (1915), Felix (1922), and others, after a careful macroscopic and histological examination of adults, babies, and foetuses, concluded that the lower intercostal nerves also innervate diaphragmatic muscle. Russell (1897), Eisler (1912), Ramström (1906), von Gössnitz (1904), and others claim the phrenic to be the sole motor nerve to the diaphragm. The last three authors regard fibres from the intercostal nerves as purely sensory. Felix, after serial section of embryos and anatomical dissections, thought that the twelfth intercostal nerve supplies the muscle fibres from the same rib and that the crural pillars are supplied by the phrenic nerves and sympathetic branches from the coeliac plexus. Cavalié found vagal fibres supplying the muscular hiatus adjacent to the oesophagus. His work has not been confirmed. Last (1954) considers from the morphology that " the crura, derivatives of the prevertebral rectus (g.v.), are supplied by the lower intercostal nerves, not by the phrenic."

Russell, in an experimental study of wry-neck, stimulated the anterior cervical roots in monkeys, and found that stimulation of the fourth produced the major contraction of the muscular portion of the diaphragm nearest to the midline. Stimulation of the sixth root caused contraction on the periphery and of the fifth in between. Schlaepfer (1923) exposed the last three intercostal nerves and stimulated each in turn under vision; the diaphragm did not contract, only the abdominal muscles. Stimulation of the left dorsal roots after laminectomy had no effect on the diaphragm. Vagal stimulations were negative.

In 1923 Schlaepfer sectioned the left phrenic nerve while doing investigations on pulmonary artery ligation in dogs, and noticed four months 
afterwards that the entire left side of the diaphragm showed signs of atrophy. Two years after phrenisection the left half was comp'etely replaced by a white fibrous membrane. Jansen (1931) repeated this in goats with the same result. Felix's suggestion that phrenic crush or avulsion would provide the definite evidence of degeneration also in man was met by Strauss in 1933, when he proved beyond doubt that the corresponding half of the diaphragm atrophied after phrenic division in man.

The association between the sympathetic system and the phrenic nerves is of interest. Boeke (1913) and Aoyagi (1913) investigated the interrelationship of muscle tone and the sympathetic system. Kuré and Shimbo (1922) claimed a trophic influence of sympathetic fibres on the diaphragm. They demonstrated a muscular atrophy and definite change in the cellular metabolism of the muscle after section of the sympathetic nerve. Aoyagi demonstrated by special staining methods sympathetic fibres in the phrenic nerves from eight bodies. Felix agreed with these observations after a study of serial sections in foetuses. Luschka (1853), Schwalbe (1881), and Merkel (1918) isolated sympathetic fibres communicating with the phrenic nerves in the neck. Schwalbe and others described the subdiaphragmatic communication between branches of the phrenic nerves and the "ganglion phrenicum" on the right side.

Phrenic crush sometimes fails to paralyse the corresponding half of the diaphragm. This may be due to incomplete crushing, isolation of the wrong nerve, or anatomical variations. Mostly, the phrenic nerve arises from C.3, 4, 5. It may receive fibres from C.1 (Krause, 1880), C.2 (Hirschfeld and Leveillé, 1853), C.3-7 (von Gössnitz, 1901), or C.8 and T.1 (Felix). It is almost always a well-defined separate stem, but may run with the hypoglossal (Luschka, 1853; Schwalbe, 1881 ; Wrisberg, 1780 ; Turner, 1893), the spinalaccessory nerve (Henle and Blaudin, quoted by Felix, 1922), the vagus (Wrisberg, 1780), and the nerve to the subclavius (Hirschfeld and Leveillé, 1853 ; Schwalbe, 1881; Merkel, 1918; Felix, 1922 ; Walsham, 1880). Russell's work suggests that these variations may even lead to paralysis of part of a hemidiaphragm. Thus, phrenic crush in the presence of an accessory phrenic nerve (C.4, 5 , or 6 from the nerve to the subclavius) will paralyse the crural fibres on one side of the hiatus while the peripheral diaphragm escapes. Various authors have also remarked on the varying relations of the phrenic nerve in the cervical region, rendering identification difficult.

\section{Conclusions}

(1) In man as well as in the animal species investigated the phrenic nerve is the sole motor innervation of the diaphragm. This also appears logical, as it is difficult to understand how a multiple nerve supply could produce functional unity in such a dynamic organ as the diaphragm.

The general appearance and termination of the phrenic nerves are very similar.

Minor variations occur that are of no practical significance. The constant finding that the posteromedial branch is the sole motor supply to the crura confirms the valuable study in 14 cadavera by Collis, Satchwell, and Abrams (1954). Failure to paralyse the diaphragm by phrenicotomy is almost surely due to anatomical variation.

(2) Communications from the intercostal, sympathetic, and vagi nerves are purely sensory.

(3) Constancy of anatomical pattern facilitates experimental procedures in laboratory animals and permits a definite surgical approach. Phrenic section is more reliable in the lower thorax. Direct stimulation or section of phrenic nerve branches, especially the postero-medial one, is possible in some animals where high branching occurs. This provides independent study of crural and dome function (Botha).

(4) The close relationship of the terminal phrenic branches to the oesophageal hiatus is established. This is of considerable importance for surgical incisions into the diaphragm as also in operative repair for sliding hiatal hernia.

(5) The phrenic nerves supply crural fibres on the ipsilateral side of the hiatus, irrespective of their origin from the right or left crus. A right phrenicotomy will not interfere with the function of the left limb of the right crus in the standard type (Botha). The left limb is by far the most important part of the hiatal margin as an extrinsic accessory mechanism to maintain " cardial " competence, and section on the right side is therefore less likely to produce a poor functional hiatus than section on the left side. Because of the wide anatomical variation of crural structure, the effect of phrenic nerve section is inconclusive in experimental studies on gastro-oesophageal competence or in patients with hiatus hernia.

\section{SUMMARY}

Anatomical dissections in man and animal species strongly suggested the phrenic nerve as the main motor supply to the diaphragm: nerve stimulation and degeneration experiments proved that it is the sole innervater. Phrenic nerve termination is described in detail. 
Probable causes for incomplete diaphragmatic paralysis after phrenic division are discussed. Sensory communications are described. Important experimental, surgical, and clinical conclusions are drawn.

I wish to acknowledge the help and facilities made available by Professor J. W. Orr, of the Department of Pathology, University of Birmingham. My grateful thanks are due to Professor F. A. R. Stammers for valuable advice and to Mr. T. F. Dee, clinical photographer to the Queen Elizabeth Hospital, for the photographs.

\section{REFERENCES}

Aoyagi, T. (1913). Mitt. med. Fak. Tokio, 10, 233.

Boeke, J. (1913). Anat. Anz., 44, 343.

Botha, G. S. Muller, and Nunn, J. F. Unpublished observations.

Cavalié (1896). J. Anat. (Paris), 32, 199.

Collis, J. L., Satchwell, L. M., and Abrams, L. D. (1954). Thorax, 9, 22.

Eisler, P. (1912). In Handbuch der Anatomie des Menschen, ed. Bardeleben, H. von, bd. 2, abt. 2, teil 1 . Fischer, Jena.
Ellenberger, W. L and Baum, H (1915). Handbuch der Anatomie der Haustiere, 14th ed. Berlin.

Felix, W. (1922). Dtsch. Z. Chir., 171, 283.

Gössnitz, W. von (1901). Denkschr. med.-naturw. Ges. Jena, 7, 207. - (1904). Jena Z. Med. Naturw., 38 (n.s. 31), 619.

Hirschfeld, L., and Leveillé, J. B. (1853). Névrologie. Baillière, Paris.

Jansen, J. (1931). Z. Anat. EntwGesch., 96, 624.

Krause, W. (1880). Handbuch der menschlichen Anatomie, Vol. 3. Anatomische Varietäten, 3rd ed. Hahn, Hanover.

Kuré, K., and Shimbo, M. (1922). Z. ges. exp. Med., 26, 190.

Last, R. J. (1954). Anatomy-Regional and Applied. Churchill, $\vec{\omega}$ London.

Luschka, H. (1853). Der Nervus Phrenicus des Menschen. Tübingen.

Merkel, F. S. (1918). Die Anatomie des Menschen. Bergmann, Wiesbaden.

Ramström, M. (1906). Arb. anat. Inst., Wiesbaden, 30, 669.

Russell, J. S. R. (1897). Brain, 20, 35.

Schlaepfer, K. (1923). Johns Hopk. Hosp. Bull., 34, 195. (1926). Anat. Rec, 32, 143.

Schwalbe, G. (1881). Lehrbuch der Neurologie (Hoffmann's Lehrbuch der Anatomie des Menschen, bd. 2, abt. 2, lief. 1). Besold, Erlangen.

Strauss, L. H. (1933). Z. Zes. exp. Med., 86, 244.

Turner, W. (1893). J. Anat. (Lond.), 27, 427.

Walsham, W. J. (1880). St Bart's Hosp. Rep., 16, 100.

Wrisberg, H. A. (1780). De Nervis Viscerum Abdominalium, Section 1. Dieterich, Goettingen. 